\title{
Epidemiological Pattern of Scabies and Its Social Determinant Factors in West of Iran
}

\author{
Mansour Nazari*, Aziz Azizi \\ Department of Medical Entomology, School of Medicine, Hamadan University of Medical Sciences, Hamadan, \\ Iran \\ Email: ${ }^{*}$ ynazari@yahoo.com
}

Received 8 June 2014; revised 25 July 2014; accepted 9 August 2014

Copyright (C) 2014 by authors and Scientific Research Publishing Inc.

This work is licensed under the Creative Commons Attribution International License (CC BY). http://creativecommons.org/licenses/by/4.0/

c) (i) Open Access

\section{Abstract}

Objectives: Scabies has a different epidemiological distribution among different communities worldwide due to different social factors, management approaches and healthcare policies. The present study came to address outbreaks of scabies according to the social factors in west of Iran. Methods: In a cross-sectional study, using the census sampling method, all consecutive patients with the primary diagnosis of scabies based on clinical manifestations referred to healthcare center throughout the two great provinces of Hamadan and Kermanshah at western Iran between March 2006 and February 2010 were enrolled into the study. The baseline characteristics were collected from recorded files at the healthcare centers or by interviewing with the affected patients. Results: Among 3,625,966 subjects covered by the two studied provinces, 177 cases of scabies (170 cases in Kermanshah and 7 cases in Hamadan) were identified by medical staff at the healthcare centers according to clinical manifestations $(85.3 \%)$ and laboratory microscopic assessments (14.7\%). The highest and the lowest prevalence rates were specified to 2009 (58.2\%) and 2008 (1.7\%). Regarding gender distribution of disease, $53.1 \%$ of men and $46.9 \%$ of women suffered from scabies with no significant discrepancy. In respect to age distribution of disease, the highest rates of scabies were revealed in the ages ranged 17 to 30 years (31.6\%), followed by younger than 17 years $(30.5 \%)$. The prevalence of scabies was dependently associated with residency in rural areas, family history of scabies, lower educational level, household density, lower monthly income, low personal hygiene, the existence of livestock or rodents at home, seasonal conditions, and movement to contaminated areas. Conclusion: West region of Iran especially Kermanshah province faced with high prevalence and this high disease burden can be determined by some potential factors such as residency in rural areas, family history of scabies, lower educational level, household density, lower monthly income, low personal hygiene, the existence of livestock or rodents at home, seasonal conditions, and movement to contaminated areas.

\footnotetext{
${ }^{*}$ Corresponding author.
} 


\section{Keywords}

\section{Scabies, Sarcoptes Scabiei, Pruritus, Epidemiology, Iran}

\section{Introduction}

Scabies is a common contagious parasitic dermatosis commonly derived from the mite Sarcoptes scabiei var hominis that is diagnosed clinically. The overall prevalence of this infection has been estimated 300 million cases annually entire the world [1]. Scabies can be frequently transmitted by skin to skin contacts, as well as through infected bedding or clothing [2]. The major clinical manifestations of Scabies disease is nightly pruritus associated with itching, particularly in the finger webs, on the flexor surfaces of the wrists, on the elbows, in the axillae, and on the buttocks and genitalia. Although the primary approach for diagnosis of Scabies is focusing clinical symptoms, but its diagnosing is based on the identification of mites extracted from lesions by scraping with a scalpel and microscopic assessment [3]. However, this approaches is not perfectly sensitive and exact diagnosis needs to employ other more confirming methods such as dermoscopy or adhesive tape test leading increase of diagnostic sensitivity and reduce of false-negative results [4] [5].

Scabies has a different epidemiological distribution among different communities due to its various management patterns and different healthcare policies. In developed communities, scabies primarily occurs in institutional settings such as prisons and long-term care facilities such as nursing homes and hospitals [1]. Besides, the prevalence rate of this infection seems to be higher in developing countries because of its improper management, the presence of predisposing conditions such as natural disasters, wars, and poverty leading overcrowding and increased rates of its transmission [6]. Thus along with its higher prevalence in the latter countries, it may result in higher mortality and morbidity because of high frequency of secondary bacterial infections resulting in sepsis [7]. Some available studies on the prevalence and main indicators of scabies in our society have been certainly specified to closed communities such as prisons with the overall prevalence rate of $2.2 \%$ [8]. Some other studies on the prevalence of this disorder among Iranian population have shown higher prevalence rate among younger ages, soldiers, low educated people (guidance school) and in urban areas [9]. However, these studies had two potential limitations: the results could not be generalized to the entire population and also epidemiological aspects and the main determinants of this infection in our population remained ambiguous. The present study came to address outbreaks of scabies according to the social factors in western Iran.

\section{Materials and Methods}

In a cross-sectional study and using the census sampling method, all consecutive patients with the primary diagnosis of scabies based on clinical manifestations referred to healthcare center throughout the two great provinces of Hamadan and Kermanshah at west of Iran between March 2006 and February 2010 were enrolled into the study. After approval of the plan the permission of both Hamadan and Kermanshah Universities of Medical Sciences and also coordination with the healthcare centers in both provinces, the baseline characteristics of the participants including demographic characteristics, educational level, occupation state, and residency were collected from recorded files at the healthcare centers. Also, other required data such as home status, monthly income, the presence of livestock or rodents in the house, history of movement to contaminated areas and environmental hygiene status were all collected by interviewing with the affected patients. In this study, both urban and rural areas in the two provinces were considered for assessment. For statistical analysis, results were reported as chi-square test (or Fisher's exact test if required) for the categorical variables. p values of 0.05 or less were considered statistically significant. All the statistical analyses were performed using SPSS version 16.0 (SPSS Inc., Chicago, IL, USA) for Windows.

\section{Results}

Among 3,625,966 subjects covered by the two studied provinces, 177 cases of scabies (170 cases in Kermanshah and 7 cases in Hamadan, Figure 1) were identified by medical staff at the healthcare centers according to clinical manifestations (85.3\%) and laboratory microscopic assessments (14.7\%). The overall prevalence of sca- 
bies infection was estimated 5 per 100,000 cases. The highest and the lowest prevalence rates were specified to 2009 (58.2\%) and 2008 (1.7\%) with no significant trend of the changes within four years of the study (Figure 2).

Table 1 showed that regarding gender distribution of disease, $53.1 \%$ of men and $46.9 \%$ of women suffered from scabies with no significant discrepancy. In respect to age distribution of disease, the highest rates of scabies was revealed in the ages ranged 17 to 30 years (31.6\%), followed by younger than 17 years (30.5\%), while only $37.9 \%$ of older affected ones suffered scabies. The patients were more resident in rural than in urban areas (82.5\% versus $17.5 \%, \mathrm{p}<0.05)$. The disease-related lesions were localized in hand $(22.0 \%)$, foot $(10.2 \%)$, and buttocks (7.9\%), whereas more than half of the patients (59.9\%) suffered from generalized lesions. Also, family history of scabies was positive in $71.8 \%$ of participants. The prevalence of this infection was significantly higher in those with lower educational level that the rate of scabies in illiterate subjects was $41.2 \%$, in cases with primary education level was $36.2 \%$, in cases with secondary education level was $9.6 \%$, and in those with higher educational level was $13.0 \%$. Also, the prevalence rate of scabies had a direct association with the number of family members (14.7\%) in families with low household density and $85.3 \%$ in those with higher household density. The existence of livestock or rodents was found in the house of $81.9 \%$ of cases. Also, $14.1 \%$ had the history of movement to contaminated areas. The highest prevalence rate of scabies was reported in spring and winter (50.3\% and 22.6\%, respectively) and the lowest rate was reported in summer (11.3\%). Studying the effects of personal hygiene on distribution of scabies showed higher rate of this infection in those with low personal hygiene status (54.2\%) in comparison with other affected patients (1.1\%). Regarding housing status, 56.5\% of

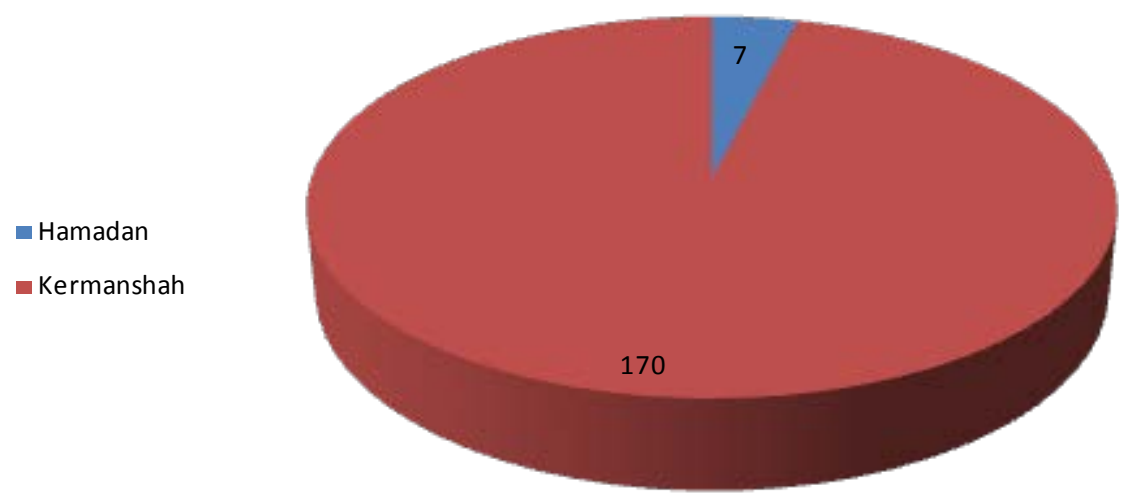

Figure 1. The frequency of scabies cases referred to health centers in Hamadan and Kermanshah from 2006-2010.

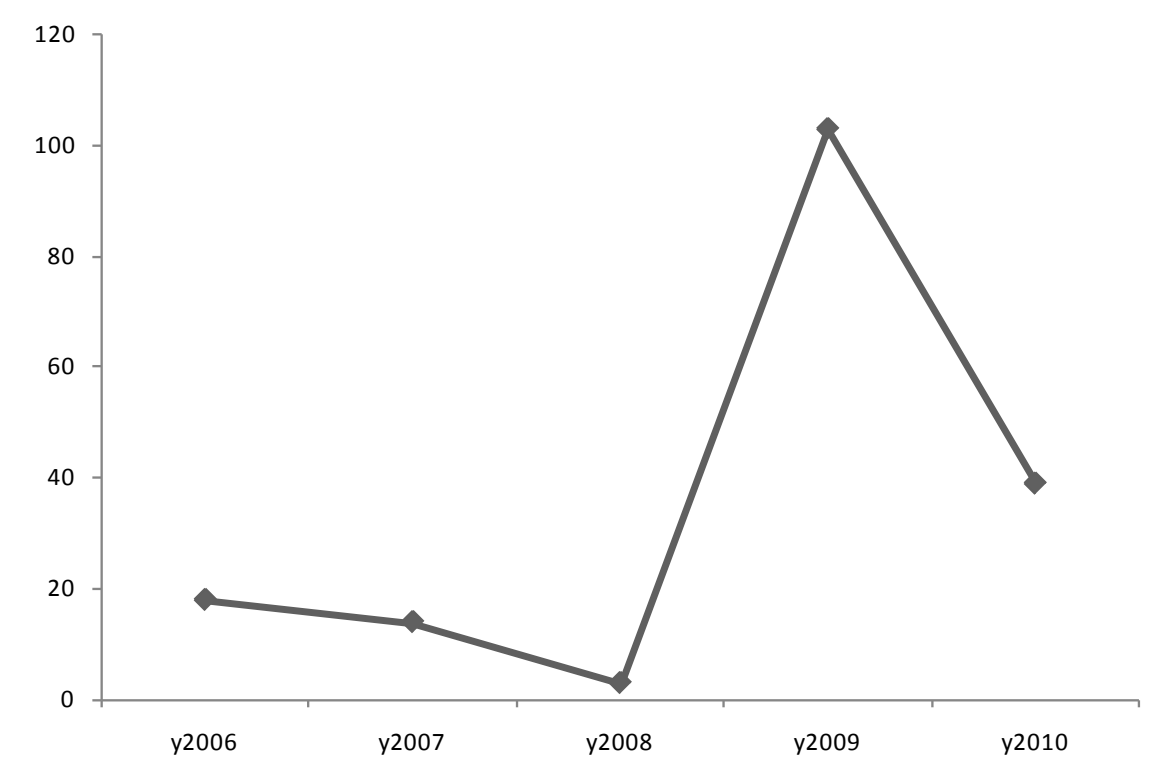

Figure 2. The trend of the changes in scabies prevalence from 2006 to 2010. 
Table 1. The frequency of some of the variables associated with Scabies in Hamadan and Kermanshah from 2006 to 2010.

\begin{tabular}{|c|c|c|c|c|}
\hline Variable & & Freq. (\%) & $\mathrm{X}^{2}$ & p-Value \\
\hline \multirow{2}{*}{ Gender } & Man & 53.1 & \multirow{2}{*}{0.684} & \multirow{2}{*}{0.408} \\
\hline & Woman & 46.9 & & \\
\hline \multirow{4}{*}{ Age } & $1-16$ & 30.5 & 17.435 & $0.002^{*}$ \\
\hline & $17-30$ & 31.6 & & \\
\hline & $31-45$ & 17.5 & & \\
\hline & $>45$ & 20.4 & & \\
\hline \multirow{2}{*}{ Resident } & Rural & 17.5 & 74.71 & $0.000^{*}$ \\
\hline & Urban & 82.5 & & \\
\hline \multirow{4}{*}{ Lesion } & Hand & 22 & 4.10 & $0.000^{*}$ \\
\hline & Foot & 10.2 & & \\
\hline & Generalized & 59.9 & & \\
\hline & Buttock & 7.9 & & \\
\hline \multirow{2}{*}{ Family History } & Positive & 71.8 & 137.08 & $0.000^{*}$ \\
\hline & Negative & 28.2 & & \\
\hline \multirow{4}{*}{ Education } & Illitrate & 41.2 & 54.48 & $0.000^{*}$ \\
\hline & Primary & 36.2 & & \\
\hline & Secondary & 9.6 & & \\
\hline & Higher & 13 & & \\
\hline \multirow{3}{*}{ Family members } & $1-4$ & 14.7 & 249.81 & $0.000^{*}$ \\
\hline & $5-7$ & 54.8 & & \\
\hline & $\geq 8$ & 30.5 & & \\
\hline \multirow{2}{*}{ Livestock } & Yes & 81.9 & 72.14 & $0.000^{*}$ \\
\hline & No & 18.1 & & \\
\hline \multirow{3}{*}{ Movement to Contaminated Arias } & Yes & 14.1 & 91.12 & $0.000^{*}$ \\
\hline & No & 85.9 & & \\
\hline & Spring & 50.3 & 64.92 & $0.000^{*}$ \\
\hline \multirow{4}{*}{ Season } & Summer & 11.3 & & \\
\hline & Autumn & 15.8 & & \\
\hline & Winter & 22.6 & & \\
\hline & Low & 54.2 & 111.70 & $0.000^{*}$ \\
\hline \multirow[t]{3}{*}{ Personal Hygiene } & Good & 44.6 & & \\
\hline & High & 1.1 & & \\
\hline & Clay & 56.5 & 87.89 & $0.000^{*}$ \\
\hline \multirow[t]{2}{*}{ Housing Status } & Brike & 42.4 & & \\
\hline & Shed-Tend & 1.1 & & \\
\hline \multirow[t]{3}{*}{ Occopational } & Farmer & 51.4 & 97.55 & $0.000^{*}$ \\
\hline & Worker & 36.7 & & \\
\hline & Unemployed & 11.9 & & \\
\hline \multirow[t]{2}{*}{ Income } & Low & 97.1 & 133.67 & $0.000^{*}$ \\
\hline & High & 2.9 & & \\
\hline
\end{tabular}

${ }^{*} \mathrm{p}<0.05$, Pearson chi-square.

affected patients had inappropriate clay home with high moisture, 42.4\% had appropriate brick houses, and $1.1 \%$ lived in sheds or tents. Regarding occupational states, $51.4 \%$ of patients were farmer or rancher. Also, 58.7\% had livestock near their place of residence. The prevalence of scabies was dramatically higher in those with lower income that $97.1 \%$ of studied families belonged to the low-income population. Moreover, 23.2\% of families had a poor hygiene status, 31.6\% had a moderate hygiene status, $44.1 \%$ had a good hygiene status, and only $1.1 \%$ had a perfect hygiene status. Regarding knowledge toward scabies and its related manifestations, only 35.0\% 
of patients had acceptable information on various aspects of disease. However, heath education in healthcare centers led to improvement of awareness about the disease and its prevention.

\section{Discussion}

According to our observation, the prevalence of scabies in our population had a wide fluctuation within the study years from $1.7 \%$ to $58.2 \%$ probably considering two different social and geographical conditions in two provinces in western Iran. Although these provinces are neighbors, but it seems that the managing approaches for prevention and control of these types of infectious epidemics have been considerably different. On the other hand and according to the present survey, more than $96.0 \%$ of affected cases were identified in Kermanshah province and only $4 \%$ of cases reported from Hamadan. Furthermore, similar to other societies, the highest prevalence was revealed in those who were younger than 30 years. Also, we found that the prevalence of scabies was dependently associated with residency in rural areas, family history of scabies, lower educational level, household density, lower monthly income, low personal hygiene, the existence of livestock or rodents at home, seasonal conditions, and movement to contaminated areas. The incidence of scabies especially in western countries has a cyclical fluctuation, affecting all ethnicities and social levels; however the trend of the incidence in developing or in resource-poor communities seems to be constant or even upward. This infection occurs in any age subgroups, but commonly seen in younger ages, particularly in school-age children with an equal sex distribution. Also, its outbreaks occur in hospitals, old-age homes and other institutions. However, the sex and age distribution of scabies is not uniform whole of the world; so more distribution in boys than in girls has been reported in some studies. Internationally, some surveys on children in East Asian population showed that the infestation rate for scabies was highest among children aged 10 - 12 years and was more commonly evident in boys (50\%) than in girls (16\%) [10]. In another observation in Libya, the incidence of scabies was slightly higher in women than in men (59\% versus $41 \%$ ), while this infection less commonly occurred in children compared with adults (37.5\% versus 62.5\%). Also, contrary to the impression, the incidence of scabies among military personnel was estimated $18 \%$ [11]. Scabies is endemic in many resource-poor communities, with a prevalence of $20 \%$ and higher. Transmission is influenced by social attitudes, migration, and access to healthcare services, housing conditions, hygiene conditions, and crowding [12]. The epidemiological pattern of disease has been however different in developed countries. In an epidemiologic study in the United Kingdom, scabies was shown to be more prevalent in urban areas and among women and children and more common in winter than in summer [13]. In a community-based survey in a kindergarten in Constance, Germany, 16 cases were identified. The attack rate was significantly higher in nursery teachers (risk ratio 42.1) compared to children (risk ratio 10.5) [14]. In another survey in Taiwan, the observed prevalence was $40 \%-80 \%$ in seven of the 19 interview districts [15]. Based on these data, the minimum estimated annual incidence of scabies in France was 328 cases per 100,000 persons [16]. In total, scabies occurrence rates vary in the recent literature from 2.71 to 46 percent. Although it is responsible for larger disease burdens and complications such as pyoderma and renal and heart disease in the tropics, scabies outbreaks contribute a significant cost to the health services managing them [17]. Thus, according to high prevalence of this disease especially in Kermanshah province, governmental policies should be changed to identify risk subgroups, as well as focus control of obtained controllable risk factors such as environmental hygiene, livestock health sites, and optimization and integration of rural residential.

West region of Iran especially Kermanshah province faced with high prevalence and this high disease burden can be determined by some potential factors such as residency in rural areas, family history of scabies, lower educational level, household density, lower monthly income, low personal hygiene, the existence of livestock or rodents at home, seasonal conditions, and movement to contaminated areas. Therefore, controllable conditions by proper health policies should be more considered to minimize the prevalence of scabies in this region.

\section{Acknowledgements}

The authors are grateful to the vice chancellor of Research in Hamadan University of Medical Sciences for the financial assistance.

\section{Authors Contributions}

MN carried out the study design, participated in data collection and drafted the manuscript. MN participated in 
the design of the study and performed the statistical analysis. MN and AA conceived of the study, and participated in its design and coordination. All authors and read approved the final manuscript.

\section{Competing Interests}

The authors declare that they have no competing interests.

\section{References}

[1] Chosidow, O. (2006) Clinical Practice. Scabies. The New England Journal of Medicine, 354, 1718-1727. http://dx.doi.org/10.1056/NEJMcp052784

[2] Haubrich, W.S. (1997) Medical Meanings: A Glossary of Word Origins. American College of Physicians, Philadelphia, 200.

[3] Dupuy, A., Dehen, L., Bourrat, E., et al. (2007) Accuracy of Standard Dermoscopy for Diagnosing Scabies. Journal of the American Academy of Dermatology, 56, 53-62. http://dx.doi.org/10.1016/j.jaad.2006.07.025

[4] Walter, B., Heukelbach, J., Fengler, G., et al. (2011) Comparison of Dermoscopy, Skin Scraping, and the Adhesive Tape Test for the Diagnosis of Scabies in a Resourcepoor Setting. Archives of Dermatology, 147, 468-473. http://dx.doi.org/10.1001/archdermatol.2011.51

[5] Albrecht, J. and Bigby, M. (2011) Testing a Test: Critical Appraisal of Tests for Diagnosing Scabies. Archives of Dermatology, 147, 494-497. http://dx.doi.org/10.1001/archdermatol.2011.59

[6] Makigami, K., Ohtaki, N., Ishii, N. and Yasumura, S. (2009) Risk Factors of Scabies in Psychiatric and Long-Term Care Hospitals: A Nationwide Mail-In Survey in Japan. The Journal of Dermatology, 36, 491-498. http://dx.doi.org/10.1111/j.1346-8138.2009.00691.x

[7] Jack, A.R., Spence, A.A., Nichols, B.J., Chong, S., Williams, D.T., Swadron, S.P., et al. (2011) Cutaneous Conditions Leading to Dermatology Consultations in the Emergency Department. The Western Journal of Emergency Medicine, 12, 551-555. http://dx.doi.org/10.5811/westjem.2010.4.1653

[8] Rahmati Roodsari, M., Malekzad, F., Ebrahimzadeh Ardakani, M., Abbasi Alai, B. and Ghoraishian, M. (2006) Prevalence of Scabies and Pediculosis in Ghezel Hesar Prison, Iran. Journal of Pakistan Association of Dermatologists, 16, 201-204.

[9] Fakoorziba, M., Amin, M., Moemenbellah Fard, M. and Najafi, M. (2012) The Frequency Rate of Scabies and Its Associated Demographic Factors in Kazerun, Fars Province, Iran. Zahedan Journal of Research in Medical Sciences, 14, 90-91.

[10] Muhammad Zayyid, M., Saidatul Saadah, R., Adil, A.R., Rohela, M. and Jamaiah, I. (2010) Prevalence of Scabies and Head Lice among Children in a Welfare Home in Pulau Pinang, Malaysia. Tropical Biomedicine, 27, 442-446.

[11] Fathy, F.M., El-Kasah, F. and El-Ahwal, A.M. (2010) Clinical and Parasitological Study on Scabies in Sirte, Libya. Journal of the Egyptian Society of Parasitology, 40, 707-731.

[12] Heukelbach, J., Mazigo, H.D. and Ugbomoiko, U.S. (2013) Impact of Scabies in Resource-Poor Communities. Current Opinion in Infectious Diseases, 26, 127-132. http://dx.doi.org/10.1097/QCO.0b013e32835e847b

[13] Downs, A.M.R., Harvey, I. and Kennedy, C.T.C. (1999) The Epidemiology of Head Lice and Scabies in the UK. Epidemiology and Infection, 122, 471-477. http://dx.doi.org/10.1017/S0950268899002277

[14] Ariza, L., Walter, B., Worth, C., Brockmann, S., Weber, M.L. and Feldmeier, H. (2013) Investigation of a Scabies Outbreak in a Kindergarten in Constance, Germany. European Journal of Clinical Microbiology \& Infectious Diseases, 32, 373-380. http://dx.doi.org/10.1007/s10096-012-1752-1

[15] Chen, C.C., Pei, K.J., Lai, Y.C. and Mortenson, J.A. (2012) Participatory Epidemiology to Assess Sarcoptic Mange in Serow of Taiwan. Journal of Wildlife Diseases, 48, 869-875.

[16] Bitar, D., Thiolet, J.M., Haeghebaert, S., Castor, C., Poujol, I., Coignard, B. and Che, D. (2012) Increasing Incidence of Scabies in France, 1999-2010, and Public Health Implications. Annales de Dermatologie et de Vénéréologie, 139, 428-434. http://dx.doi.org/10.1016/j.annder.2012.01.023

[17] Fuller, L.C. (2013) Epidemiology of Scabies. Current Opinion in Infectious Diseases, 26, 123-126. http://dx.doi.org/10.1097/QCO.0b013e32835eb851 
Scientific Research Publishing (SCIRP) is one of the largest Open Access journal publishers. It is currently publishing more than 200 open access, online, peer-reviewed journals covering a wide range of academic disciplines. SCIRP serves the worldwide academic communities and contributes to the progress and application of science with its publication.

Other selected journals from SCIRP are listed as below. Submit your manuscript to us via either submit@scirp.org or Online Submission Portal.
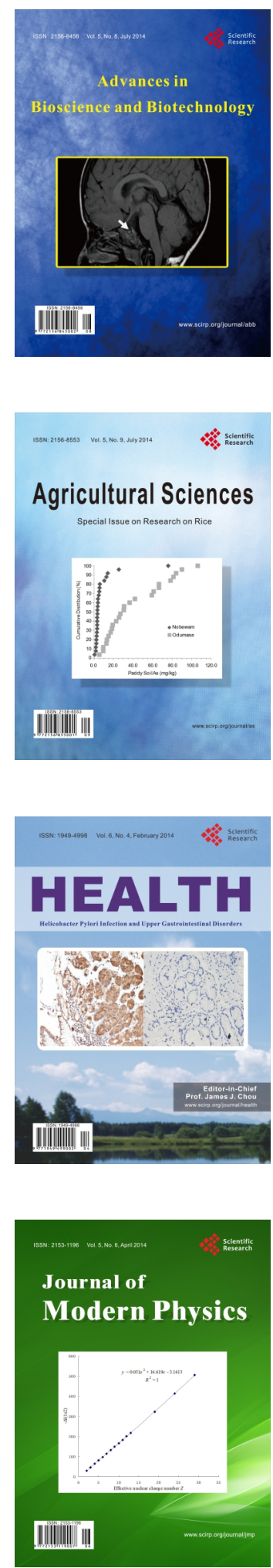
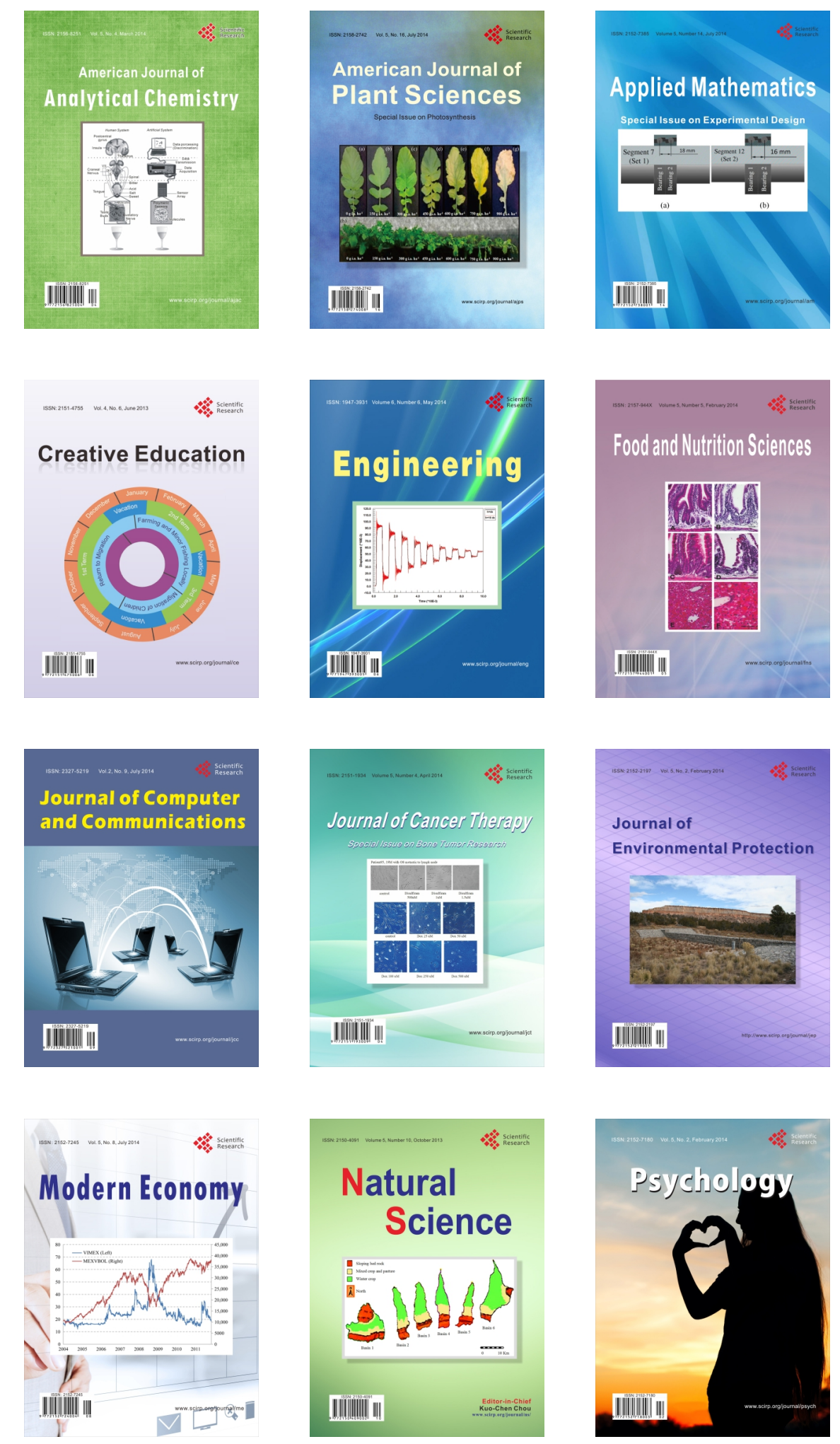